\title{
JOSÉ SOMOZA: ¿PROSA POÉTICA O POEMA EN PROSA?
}

\author{
M. ${ }^{\mathrm{a}}$ Pilar Sáenz Arenzana \\ Universidad de Zaragoza
}

Trazar la frontera entre prosa poética y poema en prosa supone inmiscuirse en límites intrincados de preceptiva literaria si nos ubicamos en los aledaños cronológicos de los años treinta y cuarenta del siglo XIX. Fechas en las que el ambiente romántico condujo a una cierta heterogeneidad que hizo aproximar la conformación formal de los géneros.

El género literario que puede enmarcarse dentro del marbete poema en prosa no surgió repentinamente sino que vio abonado su terreno por la práctica de un modo de hacer más lírico y creativo de la prosa, es decir, la llamada prosa poética. Fenómeno estético cultivado con anterioridad en las letras francesas, fruto de un deseo de renovación del lenguaje. Suzanne Bernard confirma con rotundidad, en su conocido estudio, cómo la prosa poética preparó la llegada del poema en prosa!.

A finales del siglo XVIII se intentó acercar el modo de hacer poético al prosístico; hallamos una poesía de ideas con un nuevo bagaje temático teñido de enciclopedismo sentimental, una sintaxis de largos períodos, clara, ordenada y no sometida a los rigores de la rima; es lo que Joaquín Arce explica al hablar del "prosaísmo" de la poesía dieciochesca, concepto no peyorativo sino explicativo de una estética distinta².

1.- Suzanne Bernard, Le poème en prose de Baudelaire jusqu'à nos jours, París-Nizet, 1959, p. 19:

"Prose poćtique, poème en prose, deux domaines littéraires distincts, contigus pourtant; il s'y manifeste un même désir d'emancipation, un même recours à de nouvelles forces du language. / C'est la prose poétique, premier aspect de la révolte contre les régles établies et les tyrannies formelles, qui a préparé la venue du poème en prose."

2.- Joaquín Arce, La poesía del siglo ilustrado, Madrid, Alhambra, 1981, cap. IV, p. 214 y ss. 


\section{M. ${ }^{\text {a }}$ PILAR SÁENZ ARENZ.ANA}

De igual modo, la prosa consigue a fines del siglo XVIII un tono y estilos distintos a la prosa clásica. En opinión de L. Cernuda, nuestra prosa siguió dos caminos: uno, el de la prosa que pretendió ser instrumento lírico, y otro, el de la prosa costumbrista, instrumento de la observación de la realidad ${ }^{3}$. Cernuda vio en José Somoza a uno de los prosistas que intentó utilizar la prosa como instrumento poético. Este modo de decir poéticamente se aprecia en el párrafo inicial del fragmento titulado "El risco de la Pesqueruela." Pedro Aullón de Haro, retomando la sugerencia del poeta sevillano, considera a José Somoza, junto con Pablo Piferrer, Enrique Gil y Carrasco y G. A. Bécquer, como claves en la génesis creadora del poema en prosa en España ${ }^{4}$.

Haciéndome cco de estas iniciativas críticas y tomando como punto de partida mi estudio de conjunto sobre la vida y obra de José Somozas, deseo replantear en estas líneas tales afirmaciones. Sin negar la poeticidad de la prosa del piedrahitense, considero oportuno enmarcarla en los límites de la prosa poética y no en el género del poema en prosa. Avala mi impresión lectora cl oportuno juicio de J. Gil de Biedma:

Si en Bécquer el poema en prosa todavía no existe, vano sería -habida cuenta, para decirlo en términos cernudianos, de nuestros raros y pobres esfucrzos indígenas- buscarlo en los años que antecedieron al fin de siglo, o rastrear sostenidos intentos de algo afín, en cuanto a expresividad de la prosa, a lo realizado por Baudelaire y Rimbaud 6 .

G. Díaz-Plaja, en su conocido estudio crítico y antología sobre el poema en prosa en España, acerca el género a nuestro tiempo, aunque no olvida los "intentos de modulación" de

3.- Luis Cernuda, "Bécquer y el poema en prosa español", en Poesía y literatura, II, Barcelona, Seix-Barral, 1964, p. 61-62.

4.- Pedro Aullón de Haro, "Énsayo sobre la aparición y desarrollo del poema en prosa en la literatura española", Analecta Malacitana, II, 1, 1979, pp. 109-136.

5.- Ofrezco un rápido esbozo de su perfil biográfico y creativo:

José Somoza y Muñoz nació en Piedrahita (イ́vila) el 21 de octubre de 1781. Participó en la contienda de 1808. Con el regreso de Fernando VII y su gobierno reaccionario en 1814, Somoza sufrió dos allanamientos debido a su conocida ideología liberal. Una vez restablecido el régimen constitucional en 1820, tomó parte en las tareas gubernativas como jefe político de Ávila. Con el cambio político de 1823 fue encarcelado hasta 1830. La caída del Ministerio de Cea Bermúdez, en 1834, supuso su plena libertad. En la legislación que comenzó el 20 de julio de 1834, Somoza fue nombrado procurador a Cortes por Ávila. En 1836, la encrucijada electoral unió los destinos de Somoza y Larra para conseguir el nombramiento como diputado por la provincia de Ávila, cargo que tras varias vicisitudes recayó en Somoza.

El último período de su vida se vio jalonado por dos polémicos sucesos: el intercambio epistolar que mantuvo en 1851 con el obispo de Ávila y los problemas suscitados a su muerte, el 4 de octubre de 1852, en relación con su enterramiento, que le han acarreado su fama de heterodoxo y librepensador.

Obra: se publicaron sus Obras poéticas en 1834, 1835 y 1837. En 1842 apareció una edición de sus Obras. Artículos en prosa corregida y aumentada. En este mismo año se publicó una edición de sus Poesías y del opúsculo titulado Conversación sobre la eternidad. En 1843 publicó la ninfa del Tormes y la traducción de El Temístocles de Metastasio. En 1844 apareció la novelita titulada El Capón. Somoza, como tantos escritores de su tiempo, publicó en la prensa periódica varias colaboraciones. El Semanario Pintoresco Español acoge un buen número de cllas entre 1838, 1842, 1847 y 1848. La edición de sus Obras en prosa y verso corrió a cargo de J. Lomba y Pedraja en 1904. Ediciones recientes de su obra son las compendiadas por JoséFrancisco Elvira Hernández de su Poesía (1975), El Capón (1977), su Prosa (1978) y, finalmente, La oropéndola en la fuente de la Dehesa de la Mora (1980).

6.- Jaime Gil de Biedma, "Luis Cernuda y la expresión poética en prosa", El pie de la letra. Ensayos 19551979, Barcelona, Ed. Crítica, 1980, p. 321. 


\section{JOSÉ SOMOZA: ¿PROSA POÉTICA O POEMA EN PROSA?}

la prosa artística decimonónica cuyo ejemplo más destacable de una prosa con intención poética sería el de G. A. Bécquer?

M. ${ }^{a}$ Teresa Font, en un sintético recorrido desde los orígenes franceses del poema en prosa hasta J. Ramón Jiménez, sitúa a Bécquer como precursor del género en España y afirma que esta modalidad poética se ofrece como categoría de género con el modernismo, en concreto, con Rubén Darío y su obra Azul (1888) ${ }^{8}$. Ciertamente, es a partir de finales del siglo pasado cuando nuestro poema en prosa se convierte, con palabras de Gil de Biedma, en un "fenómeno pandémico"?.

En resumen, la mayor parte de las definiciones genéricas del poema en prosa sitúan su comienzo en la literatura francesa, con Aloysius Bertrand como creador del género en su obra Gaspard de la Nuit (1842) y con Baudelaire en sus famosos Petits poèmes en prose (1869), y prosiguen citando a Bécquer, en el caso español, como antecedente de un género al que Rubén Darío da carta de naturaleza, y más adelante J. R. Jiménez abre un mayor campo de posibilidades con su Diario de un poeta recién casado. En opinión de J. Valender, las Leyendas becquerianas marcan una etapa más primitiva de la evolución del poema en prosa. Les falta la autonomía que gozan los poemas en prosa de Bertrand. Será con la influencia del modernismo cuando se cmpieza a sentir interés. La principal figura asociada a este renacimiento fue J. Ramón Jiménez, pocta inspirado en la escuela de Rubén Darío ${ }^{10}$. No obstante, hay que tener en cuenta las puntualizaciones de P. Aullón de Haro (pp. 111-112) respecto a la procedencia germánica del poema en prosa como creación del Romanticismo alemán y atender, especialmente, a la obra de Novalis, Himnos de la noche (1800).

El problema primordial que late en el fondo de estas disquisiciones fronterizas entre etiquetas genéricas es esa zona intermedia entre poesía y prosa. Interrogante que se han planteado gran parte de los preceptistas a lo largo de los siglos, a saber: ¿existe poema también en la prosa, o solamente es posible en verso? Resulta imprescindible citar aquí el enjundioso trabajo de Aurora Egido en el período que acoge la historia preceptiva de los Siglos de Oro"l. Acercándonos cronológicamente a la época en la que vivió J. Somoza, conviene mencionar el trabajo de José Domínguez Caparrós, que compila las opiniones normativas que se ocuparon de esta cuestión en los siglos XVIII y XIX. Cita un destacable elenco de preceptistas que abarcan opiniones discrepantes, ya sea la de un Luzán negando la existencia de poesía en prosa o la de un Batteux que admite la poesía sin versificación ${ }^{12}$.

7.- Guillermo Díaz-Plaja, El poema en prosa en España, Barcelona, Ed. Gustavo Gili, 1956, p. 26.

8.- M." Teresa Font, "Fl poema en prosa como género literario", en "Espacio", autobiografía lírica de Juan Ramón Jiménez, Madrid, Ínsula, 1972, cap. II, pp. 45-57.

9.- J. Gil de Biedma, op. cit., pp. 322-323: "Si en cuanto forma literaria nuestro poema en prosa sólo episódicamente alcanza a rescatarse de la marginalidad, el uso de la prosa como instrumento de virtualidades poéticas se convierte en literatura española, a partir de fin de siglo, en algo así como un fenómeno pandémico. Ya no se trata de una intención perceptible en unas cuantas páginas acá y allá, en tal o cual autor, sino una actitud creadora compartida por casi todos los grandes escritores de la época".

10.- James Valender, "El poema en prosa en España", en Cernuda y el poema en prosa, London, Támesis Books, 1984, pp. 13-21. Véase, asimismo, la entrada "poema en prosa", en A. Marchese y J. Forradellas, Diccionario de retórica, crítica y terminología literaria, Barcelona, Aricl, 1986, pp. 321-322.

11.- Aurora Fgido, "Las fronteras de la poesía en prosa", en Fronteras de la poesía en el Barroco, Barcelona, Crítica, 1990, pp. 85-114

12.- José Domínguez Caparrós, Contribución a la historia de las teorías métricas en los siglos XVIII y XIX, Madrid, C.S.I.C., 1975. Véase, especialmente, el capítulo II, apartados 1 y 2, "Prosa y verso" y "Verso y poesía", respectivamente, pp. 51 y ss. 


\section{M. ${ }^{2}$ PILAR SÁENZ ARENZANA}

La falta de precisión terminológica en la primera mitad del siglo XIX justifica la arbitraria denominación de "poemas en prosa" dada a fragmentos nada poéticos. Así, por ejemplo, Benito Vicens y Gil de Tejada califica de "poemita en prosa" a un opúsculo de Somoza titulado El bautismo de Mudarra, extenso artículo inserto en su edición de 1842 (pp. 100)136) que recrea la antigua leyenda de los infantes de Lara.

No obstante, es preciso matizar que el concepto de "poesía" que hoy tenemos difiere substancialmente del de la época que nos ocupa, puesto que nosotros no entendemos por poesía toda creación imaginativa y verosímil, según creían los autores, ya sea novela o teatro. Como consecuencia de la tradición francesa avalada en el Télémaque (1699) de Fenelon o de la prosa de Montesquieu en Le temple de Gnide (1725), surgieron imitadores de una prosa poética que terminó de configurar un nuevo ritmo en la obra de Chateaubriand ${ }^{13}$.

En la configuración de la prosa romántica es indiscutible el ejemplo de Chateaubriand. Suzanne Bernard le reserva un importante papel en la creación de una prosa como instrumento poético novedoso, aunque no lo considera autor de poemas en prosa (p. 37). Su influencia en España fue destacable, con un reconocimiento popular reflejado en la prensa y en la edición de sus obras, especialmente entre 1830 y $1854^{14}$. M. Menéndez Pelayo le dedica unas páginas, elogiosas en su conjunto, y estima "la profunda revolución que hizo en la lengua de su patria, dejando preparado un magnífico instrumento para los poetas y prosistas que vinieron después"'15.

José Somoza conoció, sin duda, la obra de Chateaubriand; su interés responde a la difusión que tuvo en la primera mitad del s. XIX, según acabo de señalar. En uno de sus artículos más interesantes - "Conversación sobre la eternidad"-16 reproduce una lectura sesgada de varios fragmentos de $\mathrm{El}$ genio del cristianismo ${ }^{17}$. Quizá de su prosa aprendió Somoza a pintar no solamente las cosas naturales, sino también el reflejo moral de cllas, y a extraer el lirismo de la descripción paisajística. Como matiza José Lomba y Pedraja, editor de la obra de Somoza:

Tomó de los franceses la claridad de la exposición, esa arquitectura perfecta de la obra literaria que ordena menudamente las proposiciones en el discurso, los párafos en la proposición, los puntos, las frases, las oraciones y las palabras ${ }^{18}$.

\footnotetext{
13.- Véase la sintética historia del término prose poem que ofrece la Princeton Fnciclopedy of Poetry and Poetics, Princeton University Press, 1975, pp. 664-665.

14.- V. E. Allison Peers, "La influencia de Chateaubriand en España", Revista de Filología Española, XI, 1924, pp. 351-382.

15.- V. M. Menéndez Pelayo, Historia de las ideas estéticas, Madrid, C.S.I.C., t. II, cap. II, "I.os iniciadores del romanticismo en Francia", pp. 692-710.

16.- Artículo fechado en Piedrahita a fines de diciembre de 1841 e incluido en su edición de 1842 aunque fue publicado aisladamente como un opúsculo. La publicación de este escrito acarreó a Somoza la fama de heterodoxo que la tradición crítica le ha asignado. Hay un ejemplar incompleto en la B.N.: José Somoza, Conversación sobre la eternidad, Madrid, Imprenta de Yenes, 1842 (B.N.: V/C 2539-11).

17.- Vizconde de Chateaubriand, El genio del cristianismo, Madrid, Jesús García Editor, 1879. Concretamente, los fragmentos elegidos corresponden a la 2," parte, "Poética del cristianismo", libro III: "Continuación de la poesía en sus relaciones con los nombres". Pasiones (pp. 199-200) y al libro IV "De lo maravilloso o de la poesía en sus relaciones con los seres sobrenaturales", capítulo II "De la alegoría" (p. 230) y capítulo VII "De los ángeles" (p. 96).

18.- José Lomba y Pedraja,"Preliminar" a Obras en prosa y verso de D. José Somoza, Madrid, Imprenta de la Revista de Archivos, Bibliotecas y Museos, 1904, pp. XIVII-XI.VIII.
} 


\section{JOSÉ: SOMOZA: ¿PROSA POÉTICA O POEMA EN PROSA?}

Una de las características más notorias de la prosa de Somoza es la presencia de lo insignificante, el elogio de la cosa pequeña. Supo recrear la visión aprehendida en un instante con técnica impresionista. En alguno de sus escritos aparece el subtítulo de "fragmento": "Memorias de Piedrahita (Fragmento)", "Mi primera sensación benéfica (Fragmento)" y "Usos, trajes y modales del siglo XVIII (Fragmento)"19. Lomba y Pedraja opina que quizá su intención fuera dar a su plan literario una mayor extensión, aunque ya nunca se extendió en una letra ${ }^{20}$.

En la paulatina creación de la prosa artística de la época romántica se observa la moda de acompañar los trabajos que se ofrecen a las revistas y periódicos con el subtítulo "fragmento". Los escritores costumbristas comentan, jocosamente, esta moda ridiculizando así las composiciones románticas que no se atienen a un género establecido o que quedan inconclusas. Interesantes son los juicios de Antonio M." Segovia ${ }^{21}$ y de "Abenámar" - Santos López Pelegrín- respecto a esta práctica literaria, al considerarla como un "comodín" con el que salir del paso ${ }^{22}$. No obstante, considero que en el caso de Somoza su fragmentarismo puede ponerse en relación con el matiz impresionista que impera en la visión de conjunto de cada anécdota cercana que narra. Su descripción es exhaustiva; hasta el más mínimo detalle está descrito de forma clara y penetrante, sirviéndose del vocablo exacto, revelador de una consciente voluntad de estilo. Somoza poseyó la "difícil facilidad", con palabras de L. Augusto de Cueto, de sugerir ideas o sentimientos con un lirismo instintivo ${ }^{23}$. Azorín, gran maestro de la pincelada impresionista, captó con admiración la sobriedad y plasticidad de las narraciones del piedrahitense ${ }^{24}$.

En torno a lo fragmentario, conviene destacar que en la conformación del poema en prosa fue A. Bertrand el precursor del "arte del fragmento" 25 del que, posteriormente, Baudelaire hará gala en la conocida dedicatoria a Arsène Houssaye defendiendo el carácter fragmentario de su obra: "Hachez-la en nombreux fragments, et vous verre $\angle$ que chacun peut exister à part"26. Cada fragmento posee una entidad propia y se concentra en un todo ce-

19.- Así consta en la antología que recogió estos textos en 1877: Eugenio de Ochoa, Apuntes para una biblioteca de escritores contemporáneos, t. II, París, Braudy, 1877, pp. 690-698.

20.- J. I omba y Pedraja, op. cit., p. XI.X.

21. - A. M." Segovia, "Un día perdido o las visitas de cumplimiento", Semanario Pintoresco Español, n. ${ }^{\circ}$ 10, 10 de marzo de 1839 , p. 77 :

"También yo sentiré en el alma que estos versos hayan gustado a mi auditorio, porque no hay más por ahora; y si han caído en gracia casualmente, me queda el escozor de no haber concluido tan afortunada composición. En fin pase por "fragmento", una vez que los "fragmentos" son tan de moda, que no sólo se recitan, se leen o se publican "fragmentos" de composiciones poéticas, sino que se escriben adrede y deliberadamente; que es como si un arquitecto se dedicara a hacer un friso o un capitel; y como si a un sastre se le ocurriese hacer un cuello de levita, o a una modista el ala de un sombrero".

22.- Citado por G. Díaz-Plaja, op. cit., p. 26: "Entre nosotros los románticos la palabrilla "fragmento" es el refugium pecatorum y el universal comodín con el que salimos en cualquier apuro. Se le ocurre a un romántico hacer una composición sin saber a quién ni por qué ni para qué. La hace y después se encuentra con que aquello es un tejido de desatinos incomprensibles. ¿Y qué hacer entonces? Coge y va y pone "fragmento", y con sólo esto y añadir en cualquier parte de la composición un centenar de puntos suspensivos, media docena de admiraciones y unos cuántos números romanos, cate a usted a Periquito hecho fraile y a mi hombre temido y reputado por un genio superior y un consumado poeta".

23.- L. Augusto de Cueto, "Bosquejo histórico-crítico de la poesía castellana en el s. XVIII", en Poetas líricos del s. XVIII, t. LXI, Madrid, Atlas, 1953, p. CCXXXII.

24.- Azorín, "Al margen de los clásicos", en Obras Completas, III, Madrid, Aguilar, 1961, p. 262.

25.- V. las razones que aduce Suzanne Bernard, op. cit., p. 71, al respecto.

26.- Petits Poèmes en prose (Le Spleen de Paris), ed. Robert Kopp, París, Gallimard, 1973, p. 21. 


\section{M. "PIL.AR SÁENZ ARENZANA}

rrado, en virtud del cual el poema en prosa adquiere una unidad orgánica garantizada por su brevedad.

Breve es el párrafo inicial del "fragmento" titulado "El risco de la Pesqueruela" (véase apéndice $\mathrm{I}^{127}$, seleccionado por Cernuda para demostrar el propósito de decir poéticamente en prosa. Este artículo se publicó en 1863 en la Revista Ibérica (t. VI, pp. 43-45), aunque fue redactado en 1834 según se infiere del propio texto. Narra retrospectivamente la persecución que sufrió Somoza en un momento de su vida debido a su manifiesta ideología liberal.

El párrafo inicial ambienta una descripción paisajística de clara iconografía romántica: el torrente helado, la luna reflejada en el estanque, el silencio nocturno, las sombras como espectros amenazadores... Es patente la presencia del tono poético en la disposición de las secuencias oracionales y en la presentación humanizada de los elementos paisajísticos que colaboran a crear el silencio nocturno. El uso de epítetos connotativos ("peña negra") o la anadiplosis ("Al pie de aquel risco reposa y medita sobre la desgraciada suerte de su patria. Patria, voz funesta...") corroboran el modo de hacer poéticamente.

El risco que da título al artículo se presenta al lector con el énfasis que confiere la reiteración del sintagma: "un risco del bosque, el risco del sepulcro, el risco de las lágrimas". Esta tríada aporta una importante connotación que conviene subrayar: de "un" risco pasamos a "el" risco, es decir, lo general se condensa en lo particular a medida que se intensifica el tono melacólico28.

En este breve preámbulo, Somoza habla desde la perspectiva de una tercera persona. Se desdobla en la voz del poeta solitario que medita sobre el concepto de patria. Sin embargo, en el párrafo siguiente escuchamos la voz de Somoza como narrador testimonial. En realidad, el cuerpo del artículo lo constituye el relato de un "cuento" que tiene como oyentes a las hermanas Acebal y Arratia ${ }^{29}$. Recrea un episodio de su historia personal enmarcado en los trágicos sucesos históricos de 1814. La reflexión sobre el liberalismo evoca un mundo de alusivas significaciones teñidas por la discordia moral.

El fragmento elegido por P. Aullón de Haro, "Elegía" (véase apéndice II), fue publicado también en la mencionada Revista Ibérica en 1863 (p. 46). Nada se sabe respecto a su fecha de composición, ni de las personas ni circunstancias a las que alude.

El título juega con la ambigüedad: por un lado, remite a un género de composición poética y, por otro, alude al rasgo etimológico que expresa el sentimiento de llanto contenido que de modo recurrente fluye en este fragmento. Comienza con el eco luisiano del "cuándo será que pueda" de la famosa oda "A Felipe Ruiz". Fray Luis de León es modelo permanente para Somoz: ${ }^{30}$. Se siente identificado con el agustino en el mismo anhelo de retiro mundano.

27.- Reproduzco los textos en sendos apéndices para facilitar la lectura interpretativa de los mismos.

28.- Merece la pena subrayar el anhelado deseo del poeta: ser sepultado en su finca, La Pesqueruela, al pie de este risco. Deseo que no pudo llevarse a efecto. Fis además un lugar significativo porque allí enterró un ejemplar de la Constitución gaditana, símbolo supremo del liberalismo.

29.- José Somoza cultivó una estrecha amistad con la influyente familia vizcaína de los Acebal y Arratia. Mantuvo una fluida correspondencia con D. ${ }^{a}$ Paula del Acebal entre 1839 y 1841 . A esta dama dedicó varias composiciones poéticas. Asistió a la tertulia madrileña que D. Francisco Acebal organizaba en su casa de la calle de Embajadores. Cf. en Pío Baroja, "Ė Diario de un protestante español del s. XIX", en Obras Completas, V, Madrid, Biblioteca Nueva, 1948, p. 1.152: "La de Acebal tenía una tertulia a la que acudían Eugenio de Ochoa, Pedro Madrazo, Pascual Gayangos y don José Somoza y Carvajal, el hereje de Piedrahita, cuando iba a Madrid".

30.- Recuérdese el "redescubrimiento" de fray luis de León en el siglo XVIII. Para ello v. William Atkinson, "Luis de León in eighteenth-century poetry", Revue Hispanique, LXXXV, 1933, pp. 363-376. 


\section{JOSÉ SOMOZA: ¿PROSA POÉTICA O POEMA EN PROSA?}

El texto consta de tres párrafos en los cuales, según P. Aullón de Haro (cf. pp. 116-117) y, en oposición al fragmento de "El risco de la Pesqueruela", no hay un motivo fundamental que sirva de "asidero plástico". Justifica su hipótesis en la configuración rítmica, ya que el fragmento se conforma mediante grupos cuantitativamente largos (suelen ser superiores a las diez unidades silábicas) con frecuencia apoyados en similicadencias internas o en construcciones anafóricas.

Puesto que no conocemos la verdadera intención de Somoza y éste es uno de los factores que delimitan qué cosa sea prosa poética y qué poema en prosa -junto a la extensión y a la unidad del texto (cf. P. Aullón de Haro, p. 109)-, cabe calificar este texto como un fragmento representativo de prosa poética.

Reitero la conveniencia de trazar un línea divisoria entre "prosa poética", cuidada, pulida, y "poema en prosa", porque éste debe rehuir toda intención didáctica o moralizante ${ }^{31}$. En Somoza es imposible eliminar la impronta pedagógica ya que el propósito didáctico se cierne en toda su producción. Recuérdese que su trayectoria vital supone un gozne entre el siglo XVIII y el siglo XIX; a la herencia dieciochesca de la ilustración se suma el móvil moralizante del costumbrismo.

El texto ofrece toda una gama de tonos apesadumbrados, aciagos. El escritor, una vez. más, hace gala de su sincera ideología liberal. Un cierto pesimismo existencial, unido al recuerdo de la muerte, proyecta su sombra en estas líneas. Estilísticamente, el texto se articula en una contraposición. Aparece la alternancia de un diálogo indirecto entre "ellos", voces anónimas, y el "yo" testimonial. El hilo discursivo sortea binomios paralelísticos que evidencian las vicisitudes de su entusiasmo cercenado por el fluir de los acontecimientos.

Este paralelismo de ideas genera un ritmo que caracteriza a la prosa poética y que constituye una modalidad primaria en la disposición rítmica de un contenido, bien para reiterar la misma idea de forma semejante pero no igual, bien para oponer ideas o palabras con la misma construcción sintáctica ${ }^{32}$. El recurso paralelístico es una especie de "ritmo de pensamiento" -con palabras de Amado Alonso-33 basado en la repetición más o menos periódica de unas frases, palabras o esquemas sintácticos. Apela más a lo intelectivo, a lo connotativo, aunque se encarne en recurrencias fónicas. Así, por ejemplo, la motivación fonética que observa P. Aullón de Haro en el tercer párrafo basada en sílabas que emplean la consonante $m$, produciendo una constante aliteración desde la primera hasta la última línea de dicho párrafo (cf. p. 118).

En la prosa poética, este ritmo de pensamicnto puede esconderse en un estribillo, en una palabra clave, en un símbolo, en una correlación o en un quiasmo ${ }^{34}$. Este primor estilístico es una herencia formal de nuestra prosa del siglo XV: la llamada "prosa del arte" por Rafael Lapesa, en la que los Soliloquios de fray Pedro Fernández. Pecha, o las obras de Diego de San Pedro y fray Antonio de Guevara, muestran un dominio técnico que sirve de

31.- Cf. esta opinión en M. ${ }^{2}$ Teresa Font, art. cit, pp. 49-50.

32.- Véase la opinión de Francisco López Estrada, "La prosa poemática", en Métrica española del s. XX, Madrid, Gredos, 1969, cap. V, p. 84 y ss.

33.- Amado Alonso, "El ritmo de la prosa", en Materia y forma en poesía, Madrid, Gredos, 1977, p. 26.5.

34.- V. Isabel Paraíso de Leal, Teoría del ritmo de la prosa, Barcelona, Planeta, 1976, p. 53. Interesa cl capítulo III dedicado a la prosa poética (pp. 87-120). "Elegía" es un texto que nos ofrece excelentes ejemplos de ritmo de pensamiento, desde la reiteración inicial a modo de estribillo del "cuándo será que pueda", siguiendo con el símbolo clásico del "templo en ruinas"; el uso del polisíndeton (y...y; ni...ni), la correlación de sintagmas y la concatenación -"... todo el mundo, y todo el mundo y tú..."-. 


\section{M. ${ }^{a}$ PILAR SÁENZ ARENZANA}

precedente a los ritmos de pensamiento y a las simetrías constructivas de muchas páginas decimonónicas ${ }^{35}$.

Este afán de simetría constructiva es recurrente en la prosa costumbrista de Somoza. Su argumentación se suele articular en un orden lógico expositivo por medio de la disposición de series paralelísticas ${ }^{36}$, de anafóricas reiteraciones en las que el uso del polisíndeton coadyuva a crear un ritmo rápido ${ }^{37}$. Propende a servirse de sintagmas trimembres en los fragmentos conclusivos de sus narraciones, quizá con la intención de graduar el microcosmos de alusiones en el epifonema didáctico, enalteciendo así un episodio anecdótico a primera vista. Cabe citar aquí una de sus piezas más logradas: "Una anécdota de Pedro Romero" (Semanario Pintoresco Español, 1842, pp. 37-38), fragmento que recrea el tópico horaciano - ut pictura poesis erit- en la consideración del arte como remedo de la vida.

Otra de las notas más destacadas de su estilo es la que definió J. Lomba y Pedraja como "un afán constante en la cadencia musical del período". Es posible extraer de su obra pasajes llenos de metricismos. Señala un fragmento del cuento titulado "La oropéndola en la fuente de la Dehesa de la Mora", publicado en el Semanario Pintoresco Español en 1848 (pp. 379$380)^{38}$.

Evidentemente, no pretendo valorar el ritmo de su prosa sólo por la inserción de metricismos; esa moda literaria afectó a la "prosa poética" dieciochesca francesa, plagada de versos blancos ${ }^{39}$. Conviene evitar errores como los que señala Daniel Devoto al comentar los problemas divisorios entre prosa y verso, "excogitando versos hasta en obras que pasan por

35.- R. Iapesa, "Un ejemplo de prosa retórica a fines del s. XIV: los soliloquios de fray Pedro Fernández. Pecha”, en Poetas y prosistas de ayer y hoy, Madrid, Gredos, 1977, pp. 9-24.

36.- Sirva de cjemplo un fragmento extraído de "El duende filósofo". V. la edición de J. Lomba y Pedraja, op. cit., pp. 163-164:"Unos seres se aquejaban de su suerte, otros solemnizaban su dicha (...). Unos se afanaban en arar, sembrar...; otros en fabricar establos...; éste me trasquila en verano, aquel me enmanta en invierno (...)".

37.- Pongo por caso un fragmento de sus "Memorias de Piedrahita" en las que las anafóricas reiteraciones se intercalan para relatar los sucesos acaecidos durante la guerra de la Independencia. V. F. de Ochoa, op. cit., p. 692: "Empecinado con los primeros franceses presos, y luego cuando el saqueo de los dragones, y cuando ahorcaron al fraile; $y$ cuando Soult puso aquí su cuartel general; y cuando llevaron en rehenes al que esté en gloria; y cuando la guinea de la niña, y cuando cayeron la lápida (...)".

Otro caso de uso de polisíndeton es el que utiliza en los fragmentos finales de sus artículos acumulando detalles. Sirva de ejemplo el fragmento que cierra "Fl árbol de la Charanga", artículo publicado en la Revista Ibérica, VI, 1963, p. 50: "Y se rieron y se levantaron todos porque oscurecía, y cada cual se retiró embozándose y encendiendo el cigarro a la candela del puesto de agua que ya enviaba su reflejo al río y al Árbol de la Charanga".

38.- J. Lomba y Pedraja, "Estudio preliminar", op. cit., p. XLVIII:

Esta oropéndola, dije/ se ha de volver a llevar/ esta tarde a la dehesal de la Mora, donde hay aquella fuente.- Sí, señor interrumpieron/ de la mora encantada/ que la noche de San Juan/ sale a peinarse a la luna./Esta fábula, les dije,/ no es tan entretenida, ni con mucho, como la que voy a referir a ustedes./ No era la mora encantadal sino encantadora y maga/ y solo dicen que se aparecía a los que se miraban en la fuente. Así es que/ los pastores y aldeanos/ se guardaban de acercarse/ solo una pobre muchachal la más boba del contornol obligada por la sed,/ y hostigada del calor/ tuvo un día la temeridad de penetrar en aquellas deliciosas sombras y arrojarse de pecho a beber en aquellas aguas frescas. Miró en el terso espejo de la fuente y vio ¡qué portento!/ uma angélica hermosura/ de sonrisa irresistible/ y cuyos negros cabellos/ ondeaban en torno de un semblante/ y de un cuello de alabastro.

39. - Ct, Isabel Paraíso de Leal, op. cit., nota 20, p. 49. 


\section{JOSÉ SOMOZA: ¿PROSA POÉTICA O POEMA EN PROSA?}

la mejor prosa de lengua castellana" 40 . No obstante, algunos críticos han dedicado su paciente estudio a aislar versos en la prosa de Azorín o de Valle-Inclán, entre otros ${ }^{41}$.

No se trata de buscar esquemas métricos aisladamente, sino de hallar elementos rítmicos que creen un clima poético conjunto. Recordemos que los rasgos distintivos del poema en prosa se ciñen al ritmo, la sonoridad y la trasposición musical. Características formales que ayudan a diferenciar el "poema en prosa" como género de otros géneros decimonónicos tales como el cuento, la balada y la leyenda; variedades éstas, en muchos casos, de una prosa poética mejor o peor perfilada ${ }^{42}$.

"Elegía" es un estimable ejemplo de prosa poética; proșa cincelada por la selección precisa de variados recursos linguiísticos: las interrogaciones retóricas, líricas y enérgicas por su posición inicial; el uso abundante de frases breves yuxtapuestas y la alternancia de discursos (directo e indirecto) que reproducen las dudas, recuerdos y anhelos del monólogo que mantiene el escritor consigo mismo. Es una prosa que participa de la estética de la sugerencia; Somoza, con cuidada naturalidad, suscita la idea a través de un ritmo que eleva este fragmento a la categoría de canto elegíaco.

Voltaire afirmó: "Qu'est-ce qu'un poème en prose, sinon un aveu d'impuissance?”‘3. En la historia de los anales literarios queda consignada la dificultad de matizar, en algunos de sus períodos, qué se entendía por prosa poética y qué por poema en prosa. Evidentemente, no es una alianza terminológica arbitraria porque prosa con intención artística se halla ya en los orígenes de nuestra literatura.

En estas líneas he tratado de ofrecer un eslabón en el intento de acercar la prosa al quehacer poético del siglo XIX. Queda fuera de dudas la voluntad de estilo de la prosa de José Somoza. La suya es una prosa que despierta en el lector la emoción encerrada en la recreación autobiográfica de lo cotidiano. Prosa poética, sí, porque con ella consiguió transcribir, poéticamente, el destello capaz de liberar a la anécdota de su banalidad.

\section{APÉNDICE I}

\section{El Risco de la Pesqueruela}

El torrente ha callado. Una columna de hielo desciende desde lo alto de la roca hasta el profundo estanque, en que la luna refleja un momento llevada rápidamente en un trono de nubes agrupadas como los precipicios que rodean la cumbre de Peña negra; cl viento, de cuando en cuando, sacude las altas copas de los robles de La Pesquertiela. Las sombras, que forman, se cruzan en el bosque como espectros amenazadores. El silencio de la noche reina melancólicamente, interrumpido sólo por el grito del cuervo posado sobre un risco del bosque, el risco del sepulcro, el risco de las lágrimas. Allí es donde termina algunas veces el pa-

40.- Daniel Devoto, "Prosa con faldas, prosa encadenada", en Edad de Oro, III, 1984, pp. 33-34.

41.- V. los trabajos siguientes: Mariano Baquero Goyanes, "Elementos rítmicos en la prosa de Azorín", Clavileño, 15, 1952, pp. 25-32. Y Rubén Benítez Claros, "Metricismos en las Comedias Bárbaras", Revista de Literatura, III, 1953, pp. 247-291.

42.- V. la opinión de Mariano Baquero Goyanes, Qué es el cuento, Buenos Aires, Ed. Columbia, 1967. pp. 39-41.

43.- Véanse las apreciaciones de Barbara Johnson en "Quelques consécuences de la différence anatomique des textes. Pour une théorie du poème en prose", Poétique, 1976, 28, pp. 450-465. 


\section{M. ${ }^{a}$ PILAR SÁENZ ARENZANA}

seo del poeta solitario; al pie de aquel risco reposa y medita sobre la desgraciada suerte de su patria. Patria, voz funesta en las habitaciones de los hombres, y que el bueno, para pronunciarla, tiene que buscar el desierto o las cavernas del monte de la Jura.

\section{APÉNDICE II}

\section{Elegía}

¿Cuándo será que vuelva a vuestras sombras, robles antiguos de La Pesqueruela? ¿Cuándo será que pueda reposar a la amable sombra de los bosques que me han visto nacer? Los hombres son injustos: y la soledad es el único refugio del hombre sincero. Ellos, en nombre del deber y de la obligación, me arrancaron de mi pacífico y modesto hogar. Ellos gritaron: "serás un cobarde y merecerás nuestra maldición, si no acudes a la voz de la patria". Y obedecí; y abandoné el ambiente puro de mis campos por el infecto ambiente de la capital. Acudí a trabajar en los escombros del santuario de las leyes: mas cuando de entre las ruinas y escombros del templo comenzaron a alzarse las llamas, que amenazaban, al parecer, incendiarle; entonces, los hombres, entonces los amigos mismos, con ceñuda frente, con ásperas reconvenciones, reprobaron mi trabajo: "tu imprudencia nos pierde" me decían; "tu hacha corta donde debe apuntalar; tu mano inconsiderada da pábulo al fuego que debes extinguir".

"O amigos inconsecuentes", les decía yo: "cuando acudí al fuego como buen vecino, no me preguntasteis si era inteligente, si confiaba en mi ciencia, si juraba concluir el edificio a despecho de los hombres y de los elementos. Si el templo perece, yo, sobre el techo incendiado, seré de los primeros a quienes la llama devore o el humo sofoque. Vuestras desgracias, vuestras calamidades, no podrían ser mayores que las mías. Esperad siquiera a ver el éxito de mi sincero afán y el de otros buenos, que trabajan en el mismo sentido que yo mismo y que tampoco podéis acusarlos, ni de mala intención para el bien público, ni de interés personal y mezquino".

Y tú, amable mujer, que debías enjugar el sudor de mi frente y acercar a mis labios el agua del consuelo, ¿por qué me rechaza tu mano y tus ojos se apartan de mí? Antes me conocías, antes me conocía todo el mundo; y todo el mundo y tú sois injustos conmigo. Nada reclamo, sino es que me ayudéis a descender en paz al sepulcro de mis antepasados. Bien pueden sin deshonor (me atrevo a decirlo) mezclarse mis huesos con los de mis mayores: ni encima de mi tumba, podrá ningún mortal poner la marca de la ignominia. 